\title{
Thick tool steel coatings with laser cladding
}

\author{
V. Ocelík, U. de Oliveira \& J. Th. M. De Hosson \\ Department of Applied Physics, Netherlands Institute for Metals \\ Research, University of Groningen, Groningen, The Netherlands
}

\begin{abstract}
This paper concentrates on thick and crack-free laser clad coatings (up to $3 \mathrm{~mm}$ ). The coating material is a chromium-molybdenum-tungsten-vanadium alloyed high-speed steel that shows high wear resistance, high compressive strength, good toughness, very good dimensional stability on heat treatment and very good temper resistance. It will be demonstrated that laser cladding of MicroMelt 23 powder offers a relatively wide processing window resulting in the formation of thick, microstructurally uniform, hard, crack- and defect- free coating on ordinary steel substrates. Microstructural observations using light and field emission gun scanning electron microscopy with EDS and EBSD attachments together with internal strain measurements using diffraction of X-rays revealed the reason for low susceptibility to crack formation. An intensive martensitic transformation inside small austenitic cells surrounded by hard carbides following the rapid solidification process compensates the tensile strain and finally results in compressive stresses at the coating surface. Laser cladding on different steels substrate geometries will be demonstrated together with hardness profiles and their dependence on cladding conditions.
\end{abstract}

Keywords: tool steel, laser cladding, microstructure, residual stress.

\section{Introduction}

Laser surface treatment includes several different techniques utilizing the heat of a laser beam acting at the surface to modify the composition and microstructure and produce a wide range of metallurgical effects [1]. Laser cladding using the powder blowing technique $[2,3]$ comprises fusion of an alloy powder layer to a substrate with minimum melting of the substrate. Melting starts at the surface and the particles being heated and melted when passing the laser beam are trapped in the melt pool. This technique is used for the deposition of alloys on 
turbine blades, engine valves, valve seats and drilling components. Although a wide variability of clad materials and substrates are reported in literature only a few shows results of laser cladding of tool steel powders on ordinary steel or cast iron substrates. Yellup [2] reported about laser deposited tool steel among other coatings with low dilution, high integrity and fine structures. Also Mazumder and co-workers [4] have shown the possibility to build 3D part from H13 tool steel using the so-called direct metal deposition technique, which is an advanced laser cladding technique with coaxial blowing powder. Reparation of moulds which have experienced severe damage during their service lifetime by local laser cladding of high-speed steel with high molybdenum content was recently reported by Navas at al. [5]. Abrasive wear behaviour of several laser clad tool steel coatings studied in work by Wang at al. [6] showed that the laser track overlapping results in different properties inside a re-heated zone in comparison with an area when material in the as clad condition exists.

In this work we present a laser clad coating made from tool steel powder originally used to form parts via powder metallurgy processes. This material is commercially known as Vanadis 23 (Udeholm) or MicroMelt 23 (Carpenter Powder Products). It is a chromium-molybdenum-tungsten-vanadium alloyed high-speed steel that shows a high wear resistance, high compressive strength, good toughness, very good dimensional stability on heat treatment and very good tempering resistance [7]. It will be demonstrated, that the laser cladding of both these powders offers a wide processing window resulting in the formation of thick, microstructurally uniform, hard, crack- and defect- free coatings on ordinary steel substrates.

\section{Experimental}

Laser cladding with a side blowing powder [3] was used in our experimental setup. Nd:YAG Rofin Sinar laser with the output power of $1.8 \mathrm{~kW}$ working in continuous regime was used as a heat source scanning the surface of the substrate materials with scanning speeds between 5 and $10 \mathrm{~mm} / \mathrm{s}$. Laser beam was defocused to form a circular beam spot with a diameter of $4 \mathrm{~mm}$. Vanadis 23 and MicroMelt 23 powders with chemical composition shown in Table 1 and particle size between 45 and $125 \mu \mathrm{m}$ were delivered to the processing zone using Sulzer Metco Twin 10C powder feeding system with a powder feeding rate between 150 and $220 \mathrm{mg} / \mathrm{s}$.

Table 1: Chemical composition of MicroMelt 23 powder from Carpenter Powder Product inspection certificate.

\begin{tabular}{|l|l|l|l|l|l|l|l|l|l|l|l|}
\hline Element & Fe & W & Mo & $\mathrm{Cr}$ & $\mathrm{V}$ & $\mathrm{C}$ & $\mathrm{Si}$ & $\mathrm{Co}$ & $\mathrm{Ni}$ & $\mathrm{Mn}$ & $\mathrm{Cu}$ \\
\hline $\mathrm{wt} \%$ & bal & 6.45 & 5.0 & 4.2 & 3.1 & 1.26 & 0.6 & 0.6 & 0.28 & 0.37 & 0.16 \\
\hline
\end{tabular}

During laser cladding the Argon was used as a carrier as well as a shielding gas in amounts of 3 and $15 \mathrm{l} / \mathrm{min}$, respectively. 30\% overlapping of individual laser tracks was used to build continuous laser coatings. Samples for 
microstructural observation were prepared by longitudinal and transversal crosssectioning, mechanical grinding and polishing. Light microscopy, as well as enhanced scanning electron microscopy based on field emission gun Philips XL model microscopes equipped with EDS, and Oriented Image Microscopy (TSL) together with XRD were used to study the coating microstructure. CSM Revetest scratch tester equipped with Vicker's indenter was used to measure the hardness at load of $4 \mathrm{~N}$.

The (311) fcc plane reflection in austenite is chosen as a suitable reflection for the characterization of macroscopic strains in our experiments because it corresponds to a high $2 \theta$ angle when $\mathrm{CuK} \alpha$ radiation is applied. $\operatorname{Sin}^{2} \Psi$ experiments were carried out in reflection mode with a Phillips X'pert X-ray system equipped with a $\mathrm{Cu}$ radiation source and side angle $\Psi$ range from $-60^{\circ}$ to $+60^{\circ}$ scanned in three different axis: $\varphi=0^{\circ}$ (longitudinal), $\varphi=45^{\circ}$ (diagonal) and $\varphi=90^{\circ}$ (perpendicular) to laser tracks cladding direction. All other experimental details as well as method for calculation of strain and stress from such measurements can be found in [8].

\section{Results and discussion}

\subsection{Laser processing and coatings production}

Both powders used in laser cladding experiments show a very stable behaviour during feeding and laser cladding and offer a relatively broad laser processing window in which they provide a regular single laser track shape and homogeneous pore-less coating after 30\% overlapping of consecutive laser tracks. Steel substrates with different compositions $(\mathrm{C} 45,100 \mathrm{Cr} 6$ and bearing steel) and geometries were tested.

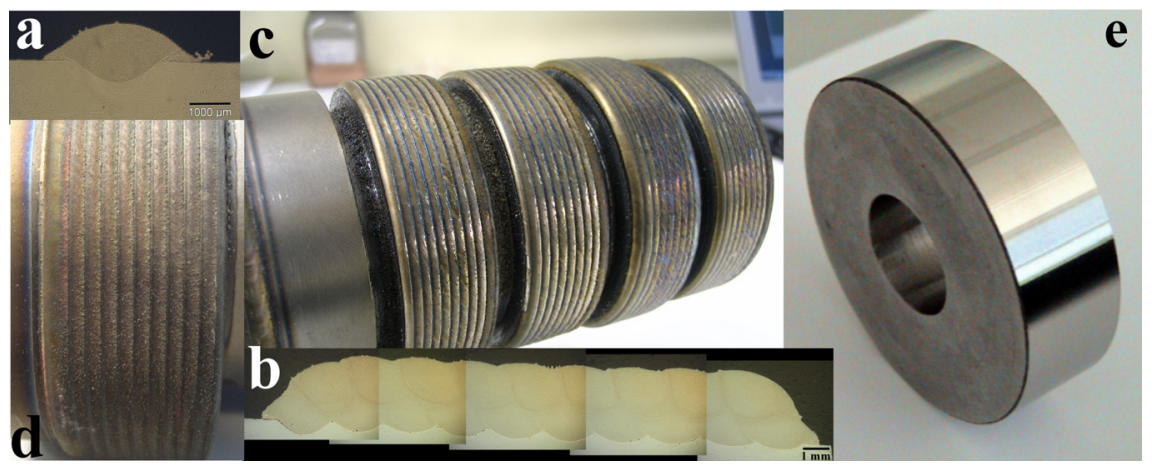

Figure 1: Laser cladding of Vanadis23 powder on C45 steel substrate. a) Single laser track profile on transversal cut; b) $3 \mathrm{~mm}$ thick coating prepared by $30 \%$ overlapping of individual laser tracks in two cladding layers; c) and d) $20 \mathrm{~mm}$ wide rings on $60 \mathrm{~mm}$ diameter bar coated by single and double layer laser cladding; e) Surface of coated ring from bar on c) after cutting, machining and grinding. 
Figure 1 demonstrates this behaviour showing the profile of an individual laser track as well as a double layer coating in their transversal cross sections. The individual laser track height of about $1 \mathrm{~mm}$ was achieved when $1750 \mathrm{~W}$ laser power, $5 \mathrm{~mm} / \mathrm{s}$ scanning speed and $150 \mathrm{mg} / \mathrm{s}$ powder feeding rate were used as main laser processing parameters during cladding on $60 \mathrm{~mm}$ in diameter C45 steel bar. The $30 \%$ overlapping of such laser tracks provides $1.3-1.5 \mathrm{~mm}$ thickness of single clad layer and 2.4-3.0 mm thick double clad layer. Very low level of internal porosity is evident from microstructural observations on different layer cuts, but also from the surface smoothness after machining, grinding and finishing of the coating surface for final use. We faced small troubles with inter-run porosity [9] between the very first laser tracks when relatively small substrates were used ( $8 \mathrm{~mm}$ in diameter bars) and when laser power has to be reduced due to the fast heating of the whole substrate piece.

\subsection{The coating microstructure}

Figure 2 shows the microstructure of the laser coating near the coating/substrate interface as well as details of the microstructure in the middle of the coating (perpendicular cross-section).
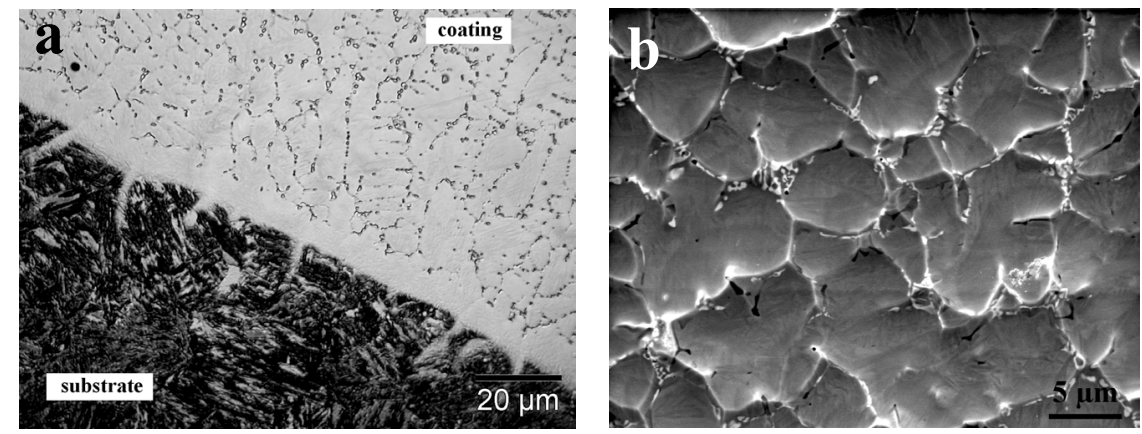

Figure 2: $\quad$ The microstructure of MicroMelt23 laser clad coating on C45 steel substrate. a) Optical microscopy of the microstructure observed near coating/substrate interface (Nital etching); b) SEM secondary electrons image of the coating microstructure.

The microstructure inside the laser track is very homogeneous with fine (5-15 $\mu \mathrm{m}$ ) iron based dendrites. Dendrite boundaries and interdendritic space is full of carbide precipitates and hard eutectic interdendritic phase. This microstructure is homogenously distributed through the whole coating, including inside and close to the laser tracks overlapping region, and the overall composition of the clad alloy measured by SEM-EDS is 4Cr-5W-3Mo-85Fe-3V (in wt $\%$ ).

The interface between coating and substrate is relatively sharp $(\sim 10 \mu \mathrm{m})$ and it consists of the thin iron based layer with local perturbations into to the substrate microstructure. 


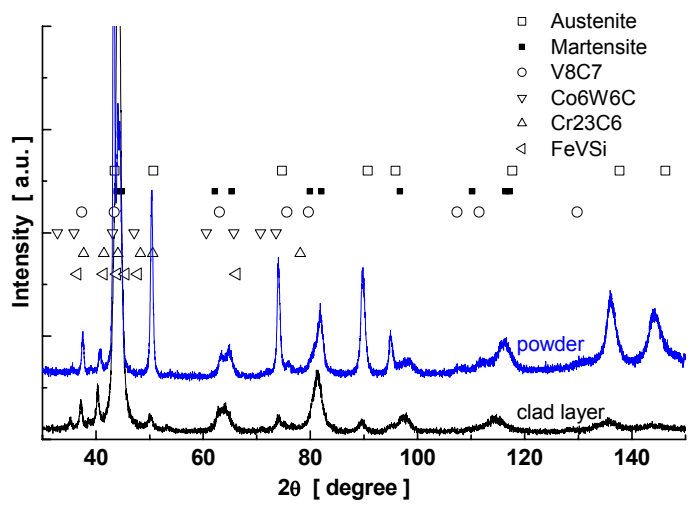

Figure 3: Comparison of X-ray diffraction spectra in $\theta-2 \theta$ set-up measured on initial powder and laser clad coating.
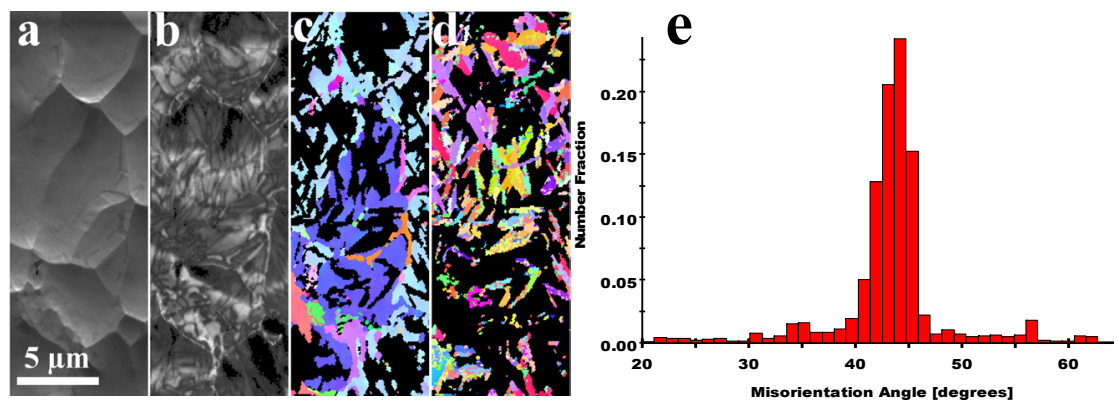

Figure 4: OIM observations of tool steel coating microstructure. a) SE image of the surface after precise ion polishing; b) Image Quality image from the same place, c) OIM image of austenite phase; d) OIM image of martensite phase; e) Misorientation angle between martensite phase inside austenitic grains.

Figure 3 shows the results of phase analysis of the laser clad coating and initial powder via $\mathrm{X}$-ray diffraction of $\mathrm{CuK} \alpha$ radiation. The similarity between the X-ray spectra of the powder and the clad layer suggests that the phase composition of the original alloy is conserved, i.e. also inside a clad layer, which means that the change melt composition due to a dilution from the substrate does not influence the phase composition of the coating. However, less content of austenitic iron phase after laser cladding is evident. Analysis of X-ray diffraction experiment and field emission gun electron microscopy observations using both secondary electron and back scatter electron detectors combined with EDS measurements leads to the conclusion, that microstructural dendrites consist of martensite and retained austenite, while hard interdendritic $\mathrm{Co}_{6} \mathrm{~W}_{6} \mathrm{C}$ and FeVSi phases were formed at the end of solidification process.

Oriented Image Microscopy (OIM) [10] based on analysis of Electron Back Scattered Pattern (EBSP) is a powerful tool for phase and crystallographic 
analysis of materials by scanning electron microscopy. We used it to quantify the amount of the martensite inside the coating and to visualize austenite and martensite grains orientations. Figure 4 summarizes results of OIM observations from one small place situated at the centre of cross-section from single laser track. Unfortunately, a relative demanding surface polishing procedure [11] requiring Precise Ions Polishing restrains more extensive OIM observations at different coating positions. Figure 4a shows an SEM observation of the surface of mechanically polished tools steel coating followed by $120 \mathrm{~min}$ polishing using $4.5 \mathrm{keV} \mathrm{Ar}{ }^{+}$ions. The surface profile is characterized by a system of hills and valleys with a local roughness of $R_{a}=41 \mathrm{~nm}$.

Black areas on the image quality (IQ) map (Fig. 4b) indicate the places, where highly tilted electron beam $\left(70^{\circ}\right)$ is shielded due the local surface roughness and no indexable Kikuchi pattern is generated. OIM maps on Fig. $4 \mathrm{c}$ and $4 \mathrm{~d}$ denote the areas, from which corresponding Kikuchi patterns were recognized as austenite and martensite, respectively. The same colour on these maps belongs to the same grain of corresponding phase. The conclusion concerning a presence of $45 \%$ of martensite in retained austenite may be drawn together with the validity of Kurdjumov-Sachs orientation relationship [12] between these two phases, as the distribution of misorientation angles between martensite and austenite grains plotted in Fig. 4e testifies.

\subsection{Hardness profiles}

Hardness, as an important characteristic that influences the wear performance, was measured to quantify the quality of the coatings.

Figure 5 characterizes the depth profile of Vicker's hardness measured through the cross-section of double layer laser coating on C45 steel substrate bar $60 \mathrm{~mm}$ in diameter. It may be concluded that in each clad layer a characteristic decrease in hardness value exists, from the value of about $820 \mathrm{HV} 0.4$ measured at the top of the layer to the value of about $730 \mathrm{HV} 0.4$ measured at its bottom. Consequently quite a sharp discontinuity in hardness value exists at the border of these two layers. Naturally, another sharp hardness change is detected at the coating/substrate interface, because of small hardening effect in Heat Affected Zone (HAZ) of massive C45 steel substrate.

Another type of the hardness profile may be observed on the single layer coating prepared on the relatively small $(8.5 \mathrm{~mm}$ in diameter) bearing steel bar as Figure 6 clearly indicates. In all four measured vertical directions (Fig. 6b), there is no substantial hardness decrease inside the coating, as it was observed in previous case (Fig. 5). Also a substantial hardening effect in HAZ is present, which moderates the hardness drop inside the substrate material. Due to a small angle between the cutting plane and the laser cladding direction, the Fig. 6a maps a change of coating thickness within one revolution during laser cladding process and it also scans the coating microstructure between two adjacent laser tracks. The graph insert in Fig. 6a shows clearly that a correlation exists between the coating thickness, which varies between 780 and $980 \mu \mathrm{m}$, and coating hardness measured at $200 \mu \mathrm{m}$ depth. 


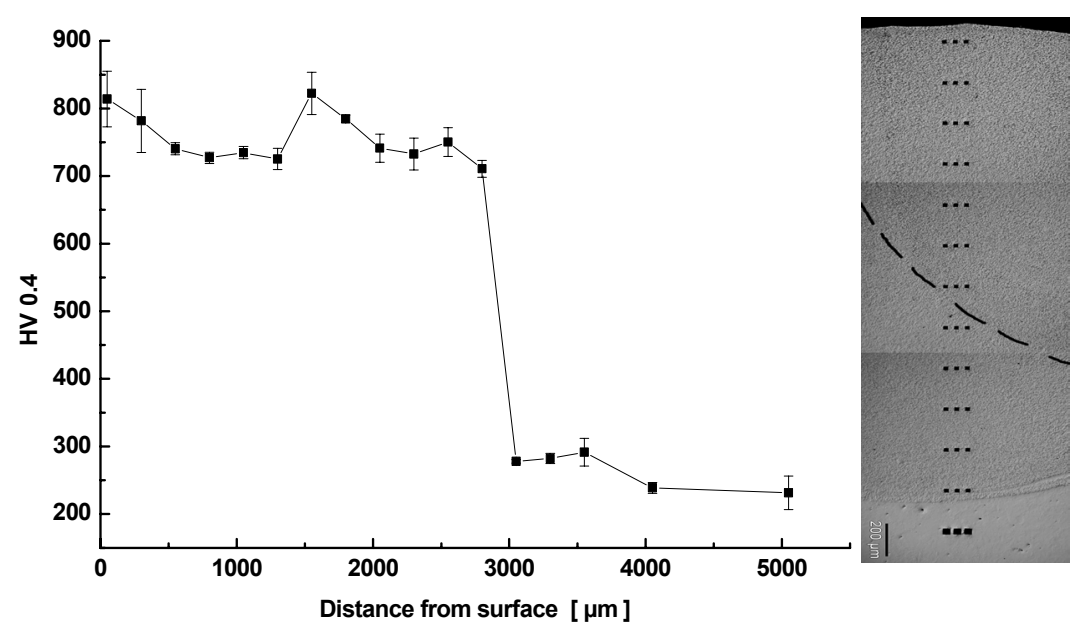

Figure 5: Microhardness profile on transversal coating cross-section plotted as an average value measured from three indents at the same depth of $2.8 \mathrm{~mm}$ thick double layer coating. Dashed line denotes microstructural boundary between laser tracks made in the first and the second laser cladding layer.
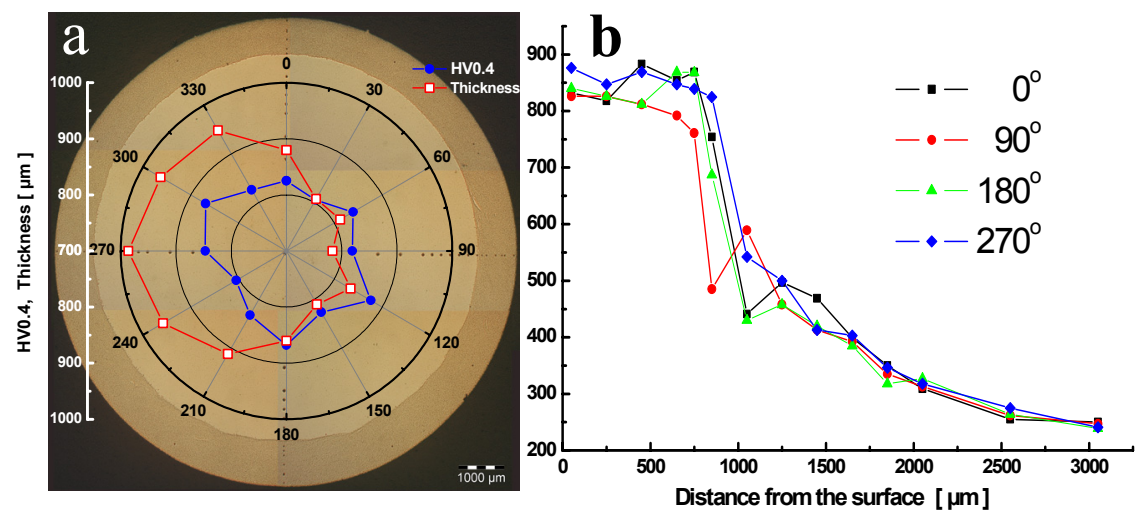

Figure 6: a) Optical micrograph of longitudinal cross section of MicroMelt 23 coating on $8.5 \mathrm{~mm}$ bearing steel bar. Insert shows the thickness and the microhardness (in depth of $200 \mu \mathrm{m}$ from the surface) dependence of the coating on the rotation angle. b) Microhardness profiles of MicroMelt 23 coating and substrate at four different angles. 


\subsection{Residual stresses}

The Vanadis 23 clad layer was ground to eliminate the macro roughness and electrochemically etched. The $\operatorname{Sin}^{2} \Psi$ technique was applied to measure the surface strain and the stress free $\mathrm{d}_{\mathrm{o}}=1.08949 \AA$ from the (311) peak of the tool steel alloy powder was used to calculate local strain. An isotropic elastic modulus $\mathrm{E}=210 \mathrm{GPa}$ and $v=0.29$ [13] was used to calculate plain stress conditions on the coating surface. The negative slopes of the plots of plane spacing $d_{(311)}$ vs. $\operatorname{Sin}^{2} \Psi$ witness the presence of compressive strains. The biaxial stress tensor was calculated and reveals that the largest principal stress lies along the direction of laser cladding track. The major and minor stress components given in $\mathrm{MPa}$ are -1100 and -600 , respectively.

\section{Discussion}

In the Fe-C system the positive effects of vanadium is directly noticed by the increase of strength and wear resistance making these alloys suitable for cutting tools and die applications. The improvement of the mechanical properties is caused by two main mechanisms: the formation of stable $\mathrm{V}$-carbides and the refinement of microstructure [14]. In a steel melt the solubility of the vanadium is quite high [15] (on the order of $6 \%$ when the carbon amount is $2 \%$ at $1425^{\circ} \mathrm{C}$ ) but it drops drastically in solid austenite $\left(0.23 \%\right.$ at $\left.727^{\circ} \mathrm{C}\right)$ and it becomes even worse when the ferritic phase is formed $\left(<0.1 \%\right.$ on $\alpha-\mathrm{Fe}$ at $\left.727^{\circ} \mathrm{C}\right)$. The strong temperature dependence of $\mathrm{V}$ solubility indicates that the $\mathrm{Fe}-\mathrm{C}-\mathrm{V}$ austenitic system is subjected to a high amount of strengthening by dispersoids where $\mathrm{V}$ plays a very important role on the formation of carbides and carbonitrides in interdendritic spaces. The growth rate of the precipitates depends on the supersaturation of vanadium and the ratio of solute concentration in the matrix [16]. A side effect of the enhanced carbide precipitation promoted by vanadium is that the microstructure becomes finer. Further refinement is promoted if a small amount of $\mathrm{N}$ is present, which causes the formation of carbonitrides that slow down the austenite-ferrite transformation and promotes nucleation to happen in place of grain coarsening [17].

The primary parameters controlling the size of the grains in austenite/ferrite transformations are the cooling rate and the amount of precipitates formed in the interdendritic spaces. When the melt is rapidly cooled austenite does not have the time to transform in ferrite and due to oversaturation of carbon, a diffusionless transformation takes place resulting in martensite. The resulting microstructure for high cooling rates is then composed of martensite, retained austenite and carbides. Because of the high solidification rates in laser cladding technique the microstructure consists typically of fine grains, supersaturation and nonequilibrium phases. However, different hardness profiles detected for coatings prepared at different laser cladding conditions witness about different content of martensite inside the coating.

Usually, residual stresses detected inside the thick Co based laser cladding coatings on both: macro [8] and micro [18] scale levels are strong tensile 
stresses, due to a substantial shrinkage after the solidification. On the other hand, the massive martensitic transformation in this tool steel material is associated with expansion and therefore it generates compressive stresses, which in this case overcomes tensile stress components. This behaviour seems to be crucial for the possibility to form the thick coating without cracking, which is often observed when thick and hard coatings are prepared by laser cladding.

Moreover, a full potential of this tool steel coating with an interesting combination of high toughness, hardness and wear resistance at elevated temperatures may be achieved, when appropriate thermal treatment recommended for powder metallurgy products [7] will be applied on the final laser clad coating.

\section{Conclusions}

Laser cladding of MicroMelt 23 and Vanadis 23 tool steel powder produces homogeneous and continuous coatings, free of defects and with a perfect adherence to ordinary steels substrates in a broad window of processing parameters. The phase analysis of the coating showed the consistent phase composition with the initial powder, indicating a minimal influence of dilution from the substrate steel. The microstructure of the laser deposited tool steel coatings contains fine dendrites, with the presence of subdendritic grains of martensite and retained austenite in approximately equal amounts and hard interdendritic phases. The stress state of the clad layer is compressive near the surface and the larger principal stress is almost parallel to the cladding direction. Large amount of martensite plates formed inside fine dendrites is responsible for the compressive stresses and suppresses the coating cracking often observed on laser clad coating with similar values of hardness and thickness.

Due to the excellent combination of hardness, toughness and wear resistance properties of powder metallurgy products made from this powder, we may expect that laser cladding is a new promising technology to produce coatings with these excellent characteristics.

\section{Acknowledgement}

This project is financed by The Netherlands Institute for Metals Research.

\section{References}

[1] Steen, W.M., Laser Material Processing, Springer-Verlag, London, 408p, 2003

[2] Yellup, J.M., Laser cladding using the powder blowing technique, Surface and Coatings Technology, 71, pp. 121-128, 1995.

[3] Ocelík, V., de Oliveira, U., de Boer, M. \& De Hosson, J.Th.M.: Thick Co based coating on cast iron by side laser cladding: Analysis of processing conditions and coating properties, Surface \& Coatings Technology, in press: http://dx.doi.org/10.1016/j.surfcoat.2006.10.044. 
[4] Mazumder, J., Schifferer, A. \& Choi, J., Direct materials deposition: designed macro and microstructure, Mat. Res. Innovat, 3, pp.118-131, 1999.

[5] Navas, C., Conde, A., Fernández, B.J., Zubiri, F. \& De Damborenea, J., Laser coatings to improve wear resistance of mould steel, Surface and Coatings Technology, 194, pp136-142, 2005.

[6] Wang, S.-H., Chen, J.-Y. \& Xue, L. A study of abrasive wear behaviour of laser-clad tool steel coatings, Surface and Coatings Technology, 200, pp.3446-3458, 2006.

[7] Vanadis 23 - Super clean, High performance powder metallurgical cold work tool steel, www.uddeholm.com/files/vanadis_23english_991019.pdf

[8] de Oliveira, U., Ocelík, V. \& De Hosson, J.Th.M., Residual stress analysis in Co-based laser clad layers by lab X-rays and synchrotron diffraction techniques, Surface and Coatings Technology, 201, pp. 533-542, 2006.

[9] Steen, W.M., Weerasinghe, V.M., \& Monson, P., Some aspects in formation of laser clad tracks, SPIE, 650, pp. 226-233, 1986.

[10] Electron Backscatter Diffraction in Materials Science, eds. Schwartz, A.J., Kumar, M. \& Adams, B.L., Kluwer Academic/Plenum Publishers, Dordrecht, 2000, 339p.

[11] Ocelík, V., Vreeling, J.A. \& De Hosson, J.Th.M., EBSP Study of reaction zone in $\mathrm{SiC} / \mathrm{Al}$ metal matrix composite prepared by laser melt injection, Journal of Materials Science, 36, (20) pp. 4845-4850, 2001.

[12] Kurdjumov, G. \& Sachs, G., Z. Phys., 64, pp. 325-343, 1930.

[13] Carvalho, N., Low friction and wear resistant coatings, Microstructure and mechanical properties, PhD Thesis, Rijksuniversiteit Groningen (2001), 126.

[14] Stacey, A., Macgillivary, H.J., Webster, G.A., Webster, P.J. \& Ziebeck, K.R.A., Measurement of residual-stresses by neutron-diffraction, Strain Analysis for Engineering Design, 20, pp. 93-100, 1985.

[15] Sil'man, G.I., Phase diagram of Fe-C-V system and its application to metallography of steels and cast irons, Metal Science and Heat Treatment 34, pp. 665-670, 1992.

[16] Yamasaki, S. \& Bhadeshia, H.K.D.H., Modelling and characterisation of V4C3 precipitation and cementite dissolution during tempering of Fe-C-V martensitic steel, Materials Science and Technology, 19, pp. 1335-1343, 2003.

[17] Lagneborg, R., Siwecki, T., Zajac S. \& Hutchinson B., The role of vanadium in microalloyed steels Scandinavian Journal of Metallurgy, 28, pp. 186-241, 1999.

[18] de Oliveira, U., Ocelík, V. \& De Hosson, J.Th.M., Microstresses and microstructure in thick Co-based laser deposit coatings, Surface and Coatings Technology, in press, http://dx.doi.org/10.1016/j.surfcoat. 2006.12.013. 